\title{
Reflexos reformistas: o ensino das humanidades na ditadura militar brasileira \\ e as formas duvidosas de esquecer
}

\section{Reflections of an Educational Reform: the teaching of the humanities in the Brazilian military dictatorship and the dubious ways to forget}

\author{
Maria do Carmo Martins ${ }^{1}$
}

\begin{abstract}
RESUMO
$\mathrm{O}$ artigo discute a reforma educacional realizada durante a ditadura militar brasileira (1964-1985) tomando como ponto de reflexão principal as mudanças curriculares e a criação das disciplinas escolares de Estudos Sociais, Educação Moral e Cívica (EMC) e Organização Social e Política do Brasil (OSPB), que conferem nova configuração ao ensino das humanidades no contexto de uma pedagogia autoritária de ênfase na tríade "formar", "cultivar", "disciplinar". Produzido a partir de revisão bibliográfica, analisa a reformar curricular como a tentativa do estado militar de produzir instrumentos visando a afinação de consciências ao poder instituído.
\end{abstract}

Palavras-chave: reforma educacional; currículo; disciplinas escolares; ditadura militar brasileira; ensino de humanidades.

\begin{abstract}
This article discusses the Educational Reform held in Brazil during the military dictatorship period (1964-1985) taking it as a point of reflection to discuss the curriculum changes and the history of school subjects: Social Studies; Civic and Moral Education (CME) and Organization of Social Policies in Brazil (OSPB), which confer a new configuration to the teaching of humanities in the context of an authoritarian Pedagogy whose emphasis
\end{abstract}

1 Universidade Estadual de Campinas. Campinas, São Paulo, Brasil. Rua Bertrand Russell, nº 801 - Cidade Universitária Zeferino Vaz. CEP 13083-865. 
was on the triad of "forming", "cultivating", "disciplining". Producing from a literature review, the author analyzes the reform curriculum as the attempt of the military state to produce instruments aiming at the pitch of consciousness to the established power.

Keywords: Educational Reform; curriculum; school subjects; Brazilian military dictatorship; humanities teaching and learning.

\section{Por que escrever sobre a ditadura militar brasileira nos seus 50 anos?}

Reescrever sobre a educação, no marco dos 50 anos da instalação do golpe de Estado e implantação da ditadura militar no Brasil (1964-1985) mostrou-se uma tarefa desafiadora, não tanto por revisitar os estudos sobre as reformas educacionais do período, tantas vezes já analisadas por distintos autores, mas, especialmente, por todo o empreendimento de fazer uma revisão sistemática e crítica de um período autoritário e violento da história recente do país. Envidei esforços no sentido de retomar antigos escritos, revisitar uma produção bibliográfica, procurando dialogar sobre o que considero ainda necessário neste ciclo de lembrar, conhecer, superar. Recorro, para isso, ao texto de Jeanne Marie Gagnebin, em seu belo livro Lembrar, Escrever, Esquecer (2006), no qual propõe o desafio de rememorar, como um modo de evitar qualquer petrificação do presente; escrever como um modo de lutar contra as forças do esquecimento, evitando enfatizar grandes sistemas interpretativos.

A característica desse período histórico, os traumas e as lutas pela memória nos levam a destacar que este "lembrar" não se insere nos atos celebrativos, mas trata-se de rememorar, acompanhando o conceito benjaminiano, que, nas palavras de Gagnebin

[...] implica certa ascese da atividade historiadora que, em vez de repetir aquilo que se lembra, abre-se aos brancos, aos buracos, ao esquecido, ao recalcado, para dizer, com hesitações, solavancos, incompletude, aquilo que ainda não teve direito nem à lembrança nem às palavras (GAGNEBIN, 2006, p. 55).

A ascese historiográfica, tarefa complexa para o período em questão, exige superar os traumas, mas também dar a conhecer cada vez mais os modos de 
operação da ditadura militar, evitando deixar o período cair no esquecimento paulatino e suave. Trata-se, antes de qualquer outra coisa, de evitar que o esquecimento duvidoso se instale. O "não-saber", o não querer saber para deixar as coisas passadas no passado, o fazer de conta que não se sabe, a denegação e o recalque são formas duvidosas de esquecer. São também armadilhas e, nesse sentido, a rememoração coloca o desafio de dar uma atenção precisa ao presente, de agir sobre o presente.

A ditadura militar no Brasil foi um período de vivência de conflitos entre projetos políticos opostos e de experiência de sofrimento. A necessidade de reconhecer que ocorria uma violência crescente, sistemática, exercida e legitimada por parte do Estado brasileiro em relação a distintos grupos sociais como os militantes de diferentes agremiações consideradas subversivas ou identificadas com a esquerda política, índios e camponeses favoráveis à reforma agrária, estudantes mobilizados contra a reforma universitária e/ou reivindicando mais democracia nos espaços educativos, trabalhadores e sindicalistas reivindicadores de direitos sociais têm pautado diversas ações no sentido de trazer à tona não somente os registros genéricos dessas ações repressoras, mas, também, o reconhecimento de que, no presente, ainda há pessoas que sofrem as heranças dessas ações.

Reconhecer que houve violação dos direitos humanos no período levou o Governo Federal a configurar, em 2011, no âmbito da Casa Civil da Presidência da República do Brasil, a Comissão Nacional da Verdade, cuja tarefa é esclarecer quais, como e sobre quem recaíram esses abusos e violações, exercidos por parte dos agentes públicos, no período de 1946 a 1988, o que inclui, portanto, todo o período da ditadura militar. Sua finalidade maior é promover uma efetiva conciliação nacional.

Tal como podemos observar na página web da Comissão Nacional da Verdade, a sua preocupação volta-se para a tarefa de promover a justiça histórica, mas também de produzir diversas parcerias com diferentes entidades, tornando possível uma maior capilaridade das ações dessa comissão (e de outras que possam vir a organizar-se) para fortalecer a democracia e o respeito aos direitos humanos, tarefas vistas como essenciais para o tempo presente ${ }^{2}$. Deste modo, torturas, desaparecimentos, ocultações, omissões envolvendo agentes públicos são enfatizados. Por outro lado, é importante ressaltar que essa mesma comissão mantém uma parceria com o Ministério da Educação do Brasil, no sentido de manter a sociedade informada de suas ações. Essa parceria explicita um dos sentidos dessa rememoração, ou seja, a ação educativa que cabe nesse lembrar e educar pela memória.

2 Disponível em: <http://www.cnv.gov.br>. Acesso em: 07/11/2013. 
Partindo destas questões sobre o rememorar e educar pela memória, ressalta-se que a ditadura militar não existiu exclusivamente como repressora ou opressora, embora estas tenham sido suas características mais traumáticas. A ditadura militar configurou-se também como um período histórico, no qual o governo brasileiro era exercido majoritariamente por militares e sua manutenção em condições de governar dependia também da capacidade de produzir políticas de estado, configurando o que se denomina um regime ditatorial.

\section{O regime militar e o imaginário social: questões da educação}

Este regime fundou-se com um golpe de Estado, estabelecendo-se por meio de sucessivo rompimento com anteriores padrões de institucionalidade política e tinha por objetivo primordial buscar um reordenamento dos rumos da sociedade e do Estado brasileiros, em direção à ordem, como já apresentado por Kaufmann e Martins (2009, p. 243-244). Era um regime com uma clara tendência a disciplinar a sociedade e suas políticas sociais eram instrumentos fundamentais neste disciplinamento.

Tais políticas, em muitas ocasiões, costumam ser analisadas de forma polarizada, entre o que produziram como "bons" resultados e o que produziram de "maus" resultados. No caso do período militar, entretanto, tais critérios de classificação de bons e maus são insuficientes e pouco atendem ao entendimento do imaginário político e social daquela época que, todavia, marca o tempo presente, e que, ao ser revisitados, nos coloca em contato e permite rememorar um passado recente. Revisitá-lo em relação ao que foi proscrito e ao que foi prescrito faz parte de um mesmo movimento que busca o entendimento do projeto total que se instalou com a ditadura.

Neste artigo, me proponho a refletir sobre a reforma da educação básica (à época denominada Ensino de $1^{\circ}$ e $2^{\circ}$ graus) abordando reformas curriculares e configurações disciplinares das humanidades para o ensino escolar. Defendo que elas devem ser analisadas à luz do processo reformista, em que não apenas instalaram-se políticas educativas de forma autoritária, mas que representam a criação de uma nova ordem educativa. Corrobora para isso a perspectiva analítica de Invernizzi e Gociol (2002), que mostram como a cultura foi uma preocupação-chave do período da ditadura militar argentina (afirmo que também vale para ao caso brasileiro), com criação de estratégias de alcance nacional e que, à repressão sistemática, soma-se a afinação de consciências ao poder instituído. As estratégias foram realizadas com planos de formação docente, criação de 
propostas curriculares, definição de conteúdos mínimos nacionais e propostas editoriais para o setor educativo que seguiram pautas ministeriais oficiais.

Soares (1994, p. 24) destaca que o golpe militar teve como motivação maior a ordem nacional e afirma que, nos discursos dos presidentes militares, sempre se deu mais atenção ao caos e à desordem do que à inflação ou à estagnação econômica, por exemplo, que seriam também efetivos motivos para preocupação do Estado. Entretanto, isto não é sinal de falta de projeto, mas o seu contrário. Como o imaginário militar, tão centrado na ordem, considerava que esta era um pré-requisito para o crescimento econômico e defendia que assegurava as bases para o conceito de segurança nacional, instaurar a ordem social e dirimir o "caos" era assunto prioritário. A ordem era elemento importante do binômio doutrinário das políticas pós-1964: desenvolvimento e segurança.

Sintoni (1999, p. 24 et seq.) amplia as discussões ao corroborar que os militares eram portadores de um projeto político próprio que, embora contivesse a reserva moral específica dos indivíduos que constituíam o grupo militar e, portanto, a ordem militar, manifestava também um imaginário social maior, uma vez que suas concepções e interpretações de mundo eram acopladas ao "real". Este autor afirma que, ao se conhecer estes elementos significativos do imaginário social militar, pode-se perceber também como eles representam os civis e como instituem paulatinamente parâmetros para o entendimento da sociedade.

Em uma das passagens de seu livro, Sintoni (1999) afirma que o coronel Ferdinando de Carvalho, um severo crítico e escritor sobre a presença e a influência do comunismo no Brasil, responsável pelo Inquérito Policial Militar 709, que resultou nos 4 volumes do livro "O Comunismo no Brasil", publicado pela Biblioteca do Exército em 1966, entende que era no setor do ensino que a ação comunista era mais acintosa. Segundo Sintoni (1999)

[...] No seu entender no Ministério da Educação funcionavam "verdadeiros centros de comunização", inspirados na "doutrina" formulada pelo Instituto Superior de Estudos Brasileiros (ISEB) e difundida por numeroso organismos controlados por comunistas como a Divisão de Educação Extra-escolar, a Campanha de Assistência ao Estudante, o Instituto Brasileiro de estudos Afro-asiáticos, o movimento de Campanha Nacional de Alfabetização e outros (SINTONI, 1999, p. 191).

Para o coronel, agremiações estudantis eram financiadas pelo próprio ministério para ampliar a onda vermelha comunista. 
Como podemos ver, considerava-se que havia motivos para os militares preocuparem-se com a educação, em especial por dentro do Estado, já que de seu interior emanava a abertura e até mesmo o financiamento para o avanço comunista.

Percebe-se também, em uma entrevista publicada por D'Araújo e Castro (1997), concedida pelo General Ernesto Geisel, Presidente da República entre os anos de 1974 a 1978, que a desordem social, a subversão e até mesmo a informalidade dos estudantes nas suas manifestações deveriam ter um olhar mais acurado e controlador por parte do Estado. Ele mostra-se indignado com a presença comunista entre os estudantes, reitera a necessidade do controle sobre eles e afirma mesmo que, ao apresentarem-se diante do Presidente para dialogar usando "mangas de camisa", mostravam certa atitude de deboche em relação ao Estado, representado por seu chefe político. Por fim, chama a atenção para a necessidade do recato e de certa mística quanto a esse contato.

Com esses dois exemplos de manifestações oriundas da cúpula do exército, o que se quer demostrar é a presença de uma representação sobre determinados setores sociais que serão especial objeto de atenção por parte desse governo durante o regime militar. Os estudantes, os órgãos relativos à educação e até mesmo o cotidiano no ensino escolar receberam atenção ampla do governo militar. Atenção que abarca as duas formas de agir dos militares: a repressão, vinculada aos movimentos e às manifestações estudantis, e o disciplinamento, associado à reforma da educação básica, com a reformulação curricular do ensino e a criação de disciplinas da área das humanidades que propõem a moralização dos costumes e a uma nova ordem interpretativa para a realidade nacional.

\section{A criação da nova concepção de humanidades visando o ensino}

A reforma da educação básica da ditadura militar compreende a reestruturação do sistema escolar, com a criação da escola do ensino fundamental de 8 anos ( $1^{\mathrm{a}}$ a $8^{\mathrm{a}}$ séries) e a reorganização dos objetivos fundamentais do ensino de $2^{\circ}$ grau, que se volta para uma formação mais profissionalizante, como expressos na Lei 5.692/71, que "Fixa as Diretrizes e Bases do Ensino de $1^{\circ}$ e $2^{\circ}$ graus e dá outras providências".

A reforma curricular, entretanto, precisa ser vista num conjunto maior de documentos, uma vez que a criação de novas disciplinas e a indicação de novos conteúdos ou matérias seguiu uma trajetória um tanto distinta. Além da própria Lei já citada, correspondem ainda os Pareceres do Conselho Federal de 
Educação no 853/71, que "Fixa o núcleocomum para os currículos do ensino de $1^{\circ}$ e $2^{\circ}$ graus, definindo-lhes os objetivos e a amplitude" e o Parecer 94/71 "Currículos e Programas de Educação Moral e Cívica", que explicita ainda mais o que deveria ser a implementação do Decreto Lei no 869/69 - "Dispõe sobre a inclusão da Educação Moral e Cívica como disciplina obrigatória nas escolas de todos os graus e modalidades do sistema de ensino no país e dá outras providências". Nesse conjunto de documentos, vê-se claramente a criação dos Estudos Sociais como matéria de ensino, a criação da Educação Moral e Cívica (EMC) como práticas educativas e, posteriormente, disciplina escolar, e uma grande reestruturação dos modelos curriculares e dos objetivos para os conhecimentos escolares que deveriam ser ensinados na escola básica.

No caso do ensino das humanidades, como nos mostra Martins (2003a, p. 161-167) algumas mudanças já estavam em curso quando o Conselho Federal de Educação criou, em 1962, a disciplina escolar de Organização Social e Política Brasileira (OSPB), que comporia a parte complementar dos currículos para o ciclo ginasial (conforme se vê no Relatório e Pareceres da Comissão Especial de Ensino Médio, março/1962). Neste caso, como nos apresenta a autora, a iniciativa do $\mathrm{CFE}$ fora anterior à reforma educacional da ditadura militar, mas mostrou-se perfeitamente adequada quando essa reforma foi efetivada, ocorrendo sua manutenção no conjunto das disciplinas escolares. É importante destacar que a parte complementar dos currículos não era a parte das disciplinas eletivas, ou seja, não era optativo oferecer; era obrigatória, prescrita para algumas séries do ensino fundamental.

Kaufmann e Martins (2009), ao referirem-se a um estudo que demonstra a colaboração dos governos brasileiros e argentinos na definição do ensino do civismo nas escolas e, em especial, por meio de conteúdos curriculares, mostram que ocorreu, no período, um aprofundamento da pedagogia centrada nos seguintes objetivos: "formar", "cultivar", "disciplinar".

Segundo as autoras, no caso argentino fatos como jornadas universitárias nas quais os traços autoritários estavam fortemente presentes, a valorização de autores cujas obras produziam sínteses de clássicas obras educacionais, extraindo deles os elementos que se coadunavam aos princípios autoritários, a formação de quadros de pessoal por meio do Plano Nacional de Aperfeiçoamento Docente e a constituição de equipes de pesquisadores, comissões assessoras e grupos acadêmicos alinhados ao governo militar foram a tônica de uma pedagogia autoritária.

No Brasil, os mesmos objetivos estiveram em jogo, mas destacam outro conjunto de estratégias, tais como o fortalecimento de conselhos e comissões favorecendo um aparato técnico-administrativo, buscando dar "legitimidade social" ao regime (como é o caso do Conselho Federal de Educação e da Comissão Nacional de Moral e Civismo); a constituição de comissões de avaliação dos 
livros educativos e a vinculação de produções desses materiais didáticos com o currículo, procurando a unicidade da relação entre teoria e prática educacional, visando o trabalho nas salas de aula; a tentativa de construir currículos, em substituição aos tradicionais programas de ensino, nos quais os discursos didáticos e pedagógicos orientassem a seleção cultural para o ensino.

Baseada ainda nesses princípios e ações, a reforma educacional reorganizou o conhecimento escolar, criando o ensino por áreas, e a proposta de ensinar os Estudos Sociais como a matéria prioritária para o ensino de história e geografia, de forma interdisciplinar, também ganhou fôlego nessa época, e em 1971, na reforma curricular, se efetiva seu ensino, que foi sistematizado por meio de currículos regionais.

Estudos Sociais, OSPB, EMC e mudanças no ensino de línguas, tornando apenas "recomendável" o ensino de uma língua estrangeira moderna na escola básica (em detrimento da obrigatoriedade de períodos anteriores), e a ênfase em que esse ensino ocorresse com a escolha do inglês, são mudanças que expressam uma nova configuração no ensino das humanidades.

Retomando a premissa de que a reforma educacional visava especialmente o ordenamento e a disciplina social, vale retomar alguns elementos dos currículos escolares que estavam presentes em Estudos Sociais, EMC e OSPB para compreendermos a preocupação com esse ordenamento e disciplinamento.

No caso da Organização Social e Política do Brasil (OSPB), Martins (2003a, p. 163-164) afirma que o parecer do Conselheiro Newton Sucupira justifica a disciplina escolar ao alertar que não havia nos currículos escolares daquele momento nenhum outro componente curricular que tratasse das relações entre o Estado e a Sociedade, tendo em vista as instituições, os direitos e os deveres dos cidadãos e o civismo que deveria reger tal entendimento. Aos estudantes, tornava-se imperativo que compreendessem a obediência às regras e o conhecimento mínimo sobre a estrutura do Estado como elementos para uma tomada de consciência desses direitos e deveres.

Concebida como uma disciplina que apresentaria o Estado por dentro, com seus princípios administrativos, sua institucionalidade, e, como afirma o conselheiro já citado "[...] a encarnação do social público", a disciplina de OSPB deveria compor a parte complementar do currículo, presente apenas em algumas das séries do $1^{\circ}$ e do $2^{\circ}$ graus, e surgir como o equivalente a um estudo da realidade social e política brasileiras. O próprio conselheiro, entretanto, destaca que não seria uma disciplina equivalente à Sociologia, tampouco como Direito Público, mas, sim, um ensino com um objetivo bem definido que era contribuir para uma educação política do homem brasileiro, dentro do espírito da democracia. 
Embora assim assinalada, a sobrevivência de OSPB mesmo quando este estado democrático esteve suspenso durante a ditadura militar, se deu, evidentemente, por ser seu conteúdo capaz de legitimar quaisquer que fossem as estruturas organizacionais do Estado, seu organograma e bases legitimadoras. $\mathrm{O}$ fato de possuir um conteúdo prescritivo calcado na racionalidade e, em especial devido ao fato da ditadura brasileira sempre buscar legitimar seus modos de governar por meio do "regime de exceção", da legislação e das normatizações, certamente assegurou a existência da disciplina durante o período aqui estudado. Em 1969, a disciplina se torna obrigatória para o $2^{\circ}$ grau do ensino. Com a Lei 5.692/71 a disciplina é mantida nos currículos escolares e passa também a ter carga horária nos currículos das escolas de $1^{\circ}$ grau. Já a Sociologia e a Filosofia, que ainda subsistiam como disciplinas no $2^{\circ}$ grau, foram abolidas.

Em sua característica meramente escolar, e sem uma disciplina acadêmica que fornecesse suporte para configuração dos conhecimentos, a OSPB agia, juntamente com a EMC, com uma característica muito mais prescritiva que os demais conteúdos escolares, uma vez que seus princípios eram especialmente os de promover o entendimento da ordem social e do organograma estatal. Dentre os seus conteúdos, destacam-se as definições dos três Poderes brasileiros - o Executivo, o Legislativo e o Judiciário, a organização administrativa do Estado, o conceito de participação, de comunidade, de sociedade. E embora, por vezes, seu conteúdo se confundisse com o de EMC, ela pode ser considerada uma disciplina muito mais racional e técnica, bastante pertinente para o modelo curricular que se estabeleceu durante a ditadura, que abraça o tecnicismo como matriz curricular e pedagógica.

A Educação Moral e Cívica, por sua vez, é uma das disciplinas escolares mais controversas dos currículos durante a ditadura militar e uma das que mais sofreu reações contrárias. Sobre ela, estudos como os de Oliveira (1982), Filgueiras (2006), Onghero (2007), Martins (2003b), Kaufmann e Martins (2009) debruçaram-se buscando historiar não apenas sua criação, mas, também, compreender os sentidos políticos que advinham de seu caráter prescritivo. O trabalho de Filgueiras (2006) chama a atenção pelo fato de mostrar que os membros do Conselho Federal de Educação mantinham-se reticentes e, por vezes, mostraram-se contrários à condição de disciplina escolar desse conteúdo, embora não se manifestassem contrários à sua prática educativa nas escolas. Do Ministério da Educação e Cultura, do Poder Executivo e do Senado Brasileiro, entretanto, as disposições eram de torná-la efetivamente uma disciplina escolar, coisa que se consolida com o Decreto-Lei 869/69, quando a Comissão Nacional de Moral e Civismo foi constituída e sua obrigatoriedade como disciplina e prática educativa foi proclamada. 
À diferença de OSPB, a Educação Moral e Cívica é retomada como um conteúdo que já existira na escola brasileira e considerada uma resposta educativa urgente para modificar o ciclo de subversão da ordem social e da desmoralização pela qual passavam as instituições tradicionais. Kaufmann e Martins (2009) escrevem sobre a EMC no Brasil e na Argentina:

As disciplinas relacionadas com a formação cívica tornaram-se instrumentos prioritariamente dedicados à consecução da homogeneização social, A implantação dessa disciplina [...] significou a imposição de um discurso essencialista, antimoderno, compatível com a concepção de uma sociedade naturalizada e sem fissuras, uma sociedade harmoniosa e composta por sujeitos que sabiam amar a pátria e eram socialmente adequados ao contexto no qual se inseriam (KAUFMANN; MARTINS, 2009, p. 247).

Seu caráter moralizante destaca-se pela vinculação não somente de uma naturalização da sociedade como espaço e tempo de convivências visando a harmonia, mas também como difusora de uma concepção essencialista, uma cosmovisão que busca difundir o espiritual e a busca da "Verdade", que se pautará por uma educação da sensibilidade humana, cuja máxima é a formação de uma consciência e o apego aos valores. Parte desse conteúdo moralizante, oriundo da retomada de obras que serviram aos propósitos religiosos, como afirma Onghero (2007, p. 122) ao estudar livros didáticos de EMC, tratava de tornar os conceitos cristãos como universais e, ao apresentarem outras religiões, as descreviam como crença exótica ou como confirmação de valores cristãos. O próprio Parecer CFE 94/71 mostra que a educação moral deveria ser confessional, não vinculada a nenhuma igreja, mas que esta educação não existiria sem a moral religiosa, uma vez que Deus seria fundamental para a maioria da humanidade formar seus valores, o que os leva a significar a EMC a ser ensinada por meio do entendimento de uma Religião Natural.

A criação destas duas novas disciplinas escolares - EMC e OSPB - ocorreu em um processo lento na década de 60 , como podemos ver, mas ambas, juntamente com os conteúdos de História e Geografia, agora integradas como Estudos Sociais nos currículos escolares, constituem, segundo o parecer 853/71, as Ciências Humanas em sua versão para o ensino.

Estudos Sociais, por sua vez, concebida como área de estudos, passa, paulatinamente e em decorrência de distintas manifestações do CFE e interpretações de diferentes Conselhos Estaduais de Educação sobre o assunto, à 
condição de disciplina escolar, na medida em que ganha espaço demarcado na grade curricular, passa a ser ensinada por um professor polivalente (e aos poucos também formado nos cursos superiores de Estudos Sociais) e que substitui a versão disciplinar anteriormente existente, com a História e Geografia ensinadas separadamente. Nos dizeres de Martins (2002, p. 112-113), é no próprio Parecer 853/71 que se define esta questão, quando afirma que a diferença entre atividades, área de estudo ou disciplina ocorre quanto mais se especificam os conteúdos e os objetivos do ensino. O CFE, por exemplo, acentua a necessidade de haver a disciplina quando os objetivos de um determinado conhecimento se tornam mais especializados.

Formada a partir da seleção de conteúdos de uma História essencialmente política, com valorização de datas e fatos marcantes para esta historiografia, recheada de indicações de uma historiografia que consagrava vultos históricos; associada às concepções de uma Geografia física e política, com pinceladas de demografia, a disciplina de Estudos Sociais expressava, de maneira bastante eloquente, a premissa de que uma disciplina é criada ou modificada quando se modificam os objetivos para seu ensino. No ensino fundamental concebia-se que os Estudos Sociais tinham por objetivo a seleção de saberes que promovessem no educando condições de uma vida em sociedade, tendo por princípios seu ajustamento e adequação à vida social, de forma cooperativa. Além disso, destacam-se entre os objetivos a capacidade dos "cidadãos" assumirem responsabilidade para com a comunidade, o Estado e a Nação, o respeito e a valorização do patrimônio histórico e cultural do país, a autoavaliação das condutas como indivíduos membros de um grupo e a transformação de condutas a partir da reformulação de conceitos.

\section{Finalizando}

Do ponto de vista educativo escolar, cabe ainda enfatizar que a criação dessas disciplinas heteróclitas está assentada em elemento importante da estrutura e do planejamento do trabalho pedagógico, que é o currículo. Compreendida como aquele elemento que visa orientar os processos educativos e, fortemente impregnada, à época, dos princípios de racionalidade, gestão, eficácia, a prescrição curricular foi um dos maiores pilares que sustentaram o imaginário ordeiro e disciplinador do período. Perceber essas prescrições é compreender também como o Estado visa assegurar sua capacidade de oferta e regulação do ensino público, além de demarcar as novas configurações de poder na definição dos 
conteúdos educativos. As disciplinas criadas para o ensino, entretanto, não têm seu correspondente acadêmico, científico e não se pode dizer que se tratava de uma operação didática, responsável por tornar conteúdos científicos de forma original ou divertida.

Ao contrário, percebe-se um amplo afastamento entre os conteúdos curriculares acadêmicos e os conteúdos curriculares escolares. Pode-se mesmo dizer que, neste caso, as disciplinas escolares se mostravam pela demarcação de sua existência em um quadro ou grade curricular, com espaço específico para aulas. Cabe ainda lembrar que, nesse período, dada a necessidade de formar professores que pudessem atuar na docência dessas disciplinas, foram criados cursos de licenciatura curta, como a de Estudos Sociais, e que esses cursos superiores, tampouco, se constituíam em referências epistemológicas, disciplinares, acadêmicas ou científicas. Mas é certo que formaram muitos professores que, frequentadores desses cursos generalistas, acabavam por dar aulas sem mostrar as estratégias de produção dos conhecimentos que informavam os conteúdos que tinham que ensinar.

Retomando então a premissa de Kaufmann e Martins (2009) de que foi por base numa pedagogia que enfatiza o "formar", "cultivar", "disciplinar" que a educação na ditadura militar se consolidou, temos no ensino das humanidades uma atenção especial, pois nela se encontra o maior conjunto de representações sobre o social. Formar para a adequação, cultivar a cooperação, disciplinar o espírito e espelhar-se nas condutas foram os elementos da linha de frente desse período autoritário. Estas questões, juntamente com as revelações sobre a repressão, podem indicar algum percurso para rememorar a ditadura, permitindo ao leitor procurar nelas permanências discursivas que possam esclarecer o tempo presente, em especial o ideal prescritivo que se amplifica durante o período, com a produção volumosa de documentos orientadores de currículos.

Considero ainda que retomar estes assuntos, nestes 50 anos de instalação do golpe militar, permite retomar os sentidos das políticas tão "eficientistas" e controladoras. Se, como nos ensina Hanna Arednt, o sentido da política é a liberdade, no caso da ditadura militar o sentido da política educativa se distanciava deste princípio filosófico de forma plena, mas passava por uma importante manobra de conversão, de ressignificação. As políticas curriculares se assentavam em conteúdos que não tanto afirmavam a liberdade, já que esta não era o que mais se procurava no período, mas dirigiam a formação para os limites da liberdade, ou seja, para a responsabilidade que cabia no civismo, a importância da moral e a participação em uma sociedade que se desenvolvia a partir de linhas condutoras desde o Estado. Retomar estas discussões possibilita afastar algumas das formas duvidosas do esquecer. 


\section{REFERÊNCIAS}

BRASIL. Conselho Federal de Educação. Relatório e Pareceres da Comissão Especial de Ensino Médio. Revista Documenta, Brasília, DF, n. 1, mar. 1962.

. Decreto-Lei no 869, de 12 de setembro de 1969. Dispõe sobre a inclusão da Educação Moral e Cívica como disciplina obrigatória nas escolas de todos os graus e modalidades do sistema de ensino no país e dá outras providências. Diário Oficial da União, Brasília, DF, 15 set. 1969.

. Lei n ${ }^{\circ} 5.692$, de 11 de agosto de 1971. Fixa as Diretrizes e Bases do Ensino de $1^{\circ}$ e $2^{\circ}$ graus, e da outras providências. Diário Oficial da União, Brasília, DF, 12 ago. 1971.

. Conselho Federal de Educação. Parecer no 94/71. Currículos e Programas de Educação Moral e Cívica. Revista Documenta, Brasília, DF, n. 129, ago. 1971.

. Conselho Federal de Educação. Parecer no 853/71. Fixa o núcleo-comum para os currículos do ensino de $1^{\circ}$ e $2^{\circ}$ graus, definindo-lhes os objetivos e a amplitude. Revista Documenta, n. 132, Brasília, DF, nov. 1971.

D’ARAÚJO, M. C; CASTRO, C. (Orgs.). Ernesto Geisel. Rio de Janeiro: FGV, 1997.

FILGUEIRAS, J. M. A Educação Moral e Cívica e sua produção didática - 1969-1993. Dissertação (Mestrado em Educação: História, Política e Sociedade) - Pontifícia Universidade Católica de São Paulo, São Paulo, 2006.

GAGNEBIN, J. M. Lembrar, escrever, esquecer. São Paulo: 34, 2006.

INVERNIZZI, H.; GOCIOL, J. Un golpe a los libros. Represión a la cultura durante la última dictadura militar. Buenos Aires: EUDEBA, 2002.

KAUFMANN, C.; MARTINS, M.C. Ditaduras militares argentina e brasileira: colaborações culturais em educação na década de 1970 do século XX. In: VIDAL, D. G.; ASCOLANI, A. (Orgs.). Reformas Educativas no Brasil e na Argentina: ensaios de história comparada da educação. São Paulo: Cortez, 2009.

MARTINS, M. C. A História prescrita e disciplinada nos currículos escolares: quem legitima esses saberes? Bragança Paulista: EDUSF. 2002.

. As humanidades em debate: a reformulação curricular e a criação de novas disciplinas escolares. In: OLIVEIRA, M. A T.; RANZI, S. M. F (Orgs.). História das disciplinas escolares no Brasil: contribuições para o debate. Bragança Paulista: EDUSF, 2003a.

. Currículo, cultura e ideologia na ditadura militar brasileira: demarcação do espaço de atuação do professor. In: CERRI, L. F. (Org.). O ensino de história e a ditadura militar. Curitiba: Aos Quatro Ventos, 2003b. 
OLIVEIRA, M. A. F. B. A implantação da Educação Moral e Cívica no ensino brasileiro em 1969. Dissertação (Mestrado em Educação) - Faculdade de Educação, Universidade de São Paulo, São Paulo, 1982.

ONGHERO, A L. Moral e Civismo nos curriculos das escolas dos oeste catarinense: memórias de professores. Dissertação (Mestrado em Educação) - Universidade de Campinas, Campinas, 2007.

SINTONI, E. Em busca do inimigo perdido: construção da democracia e imaginário militar no Brasil (1930 -1964). São Paulo: Cultura Acadêmica, 1999.

SOARES, G. A. D. O golpe de 64. In: SOARES, G. A. D.; D’ARAÚJO, M. C. (Orgs.). 21 anos de regime militar: balanços e perspectivas. Rio de Janeiro: FGV, 1994.

Texto recebido em 12 de janeiro de 2014 . Texto aprovado em 06 de fevereiro de 2014. 